\title{
Ciudades y aldeas del Nuevo Mundo en los documentos de los mercaderes y viajeros italianos del Quinientos*/
}

\author{
Towns and Villages of the New World in the Papers \\ of Italian Merchants and Travelers \\ of the Sixteenth Century
}

Angela Orlandi

Universitá di Firenze

Se intenta aclarar la formación de los centros urbanos y agrícolas del Nuevo Mundo a través de los documentos de los viajeros italianos en las Américas durante el siglo XVI. Los viajeros describían los procesos constructivos de ciudades y aldeas. De estos relatos emerge una situación que, aunque no exhaustiva, presenta interesantes aspectos de las arquitecturas de las casas, de las estructuras productivas y de edificios públicos o religiosos que, en algunos casos parecían influenciadas por el gusto del Renacimiento italiano.

Palabras Claves: Mercaderes; Viajeros; Ciudades; Pueblos; Nuevo Mundo; Caribe; Ingenios azucareros; Siglo XVI.

The aim of this paper is to examine the formation of urban and rural centers and agricultural landscapes in the New World through the accounts of Italian travelers to the Americas during the sixteenth century, whereby they described the building techniques used in towns and villages. Although not exhaustive, the picture that emerges presents an interesting perspective on the architectural style of houses, manufacturing facilities and public or religious buildings, which in some cases seem to be by inspired by the Italian Renaissance.

KEYwORDS: Merchants; Travelers; Towns; Villages; New World; Caribbean; Sugar Mills; 16th Century.

* El presente artículo ha sido traducido del italiano por Javier Sanz Muro, Universidad de Siena. 


\section{Introducción}

En la época de los grandes descubrimientos la realidad de la Italia centro-septentrional se encontraba muy estimulada por el conocimiento y por las inversiones que empujaban a mercaderes y artesanos, pero también a intelectuales, diplomáticos y religiosos a la vía de las Américas. En este artículo ofrecemos alguna noticia sobre los procesos de formación de los nuevos núcleos urbanos y agrícolas a través de las historias de personajes italianos no siempre conocidos que, dispuestos a confrontarse con una realidad no siempre fácil, llegaron a las Indias Occidentales a la búsqueda de nuevas oportunidades y aventuras.

Es conocido cómo sobre todo los toscanos, «mercaderes con la pluma en la mano», prestaron una gran atención a los intercambios epistolares porque sabían bien lo importante que era escribir y recibir informaciones continuamente, no solo para satisfacer su ávida curiosidad, sino también y en especial para elaborar estrategias económicas de éxito. ${ }^{1}$

La correspondencia se movía entre países y personalidades diversas que, en un extraordinario y múltiple entrelazamiento de ciudades y de corresponsales, se intercambiaban y difundían ideas, modos de vida y conocimientos. ${ }^{2}$ Entre las dos orillas del Atlántico, cada escrito aparece a veces como una historia en la que los motivos y los contenidos que unían a los dos corresponsales se diluían en la descripción y en el comentario de los contextos observados. Además de noticias económicas o vicisitudes personales, se encuentran cuestiones políticas o institucionales, sociales o religiosas y con ellas, para señalar lo que interesa en este caso, los trazados ambientales y paisajísticos de los territorios descubiertos.

Concentraremos nuestra atención sobre todo en la descripciones que nuestros viajeros hacían de los asentamientos habitados, de los núcleos construidos y poblados por los indígenas, pero también de ciudades y pueblos que los españoles estaban levantando en algunas zonas del Nuevo Mundo.

Tenemos que ser conscientes del valor limitado de estos testimonios, útiles por las informaciones que ofrecen aunque parciales y fragmentarios, que tenemos que integrar con relaciones de viajes similares, diarios y crónicas. Algunas son relaciones escritas después de su vuelta a la patria como

1 Orlandi, 2008, 14-15

2 Idem. 
la de Galeotto Cei, mercader florentino que desde 1539 hasta 1553 recorrió sin suerte varias partes de América y que contó su experiencia cuando ya había regresado a Toscana. No podemos excluir que en aquellos escritos algunos recuerdos se hubieran empañado o que otros hayan sido acentuados para golpear la imaginación del lector. Probablemente también el milanés Girolamo Benzoni, uno de los muchos aventureros que zarparon para las Indias Occidentales con la esperanza de enriquecerse, redactó su Histori $^{3}$ a su vuelta a Europa, integrando y reforzando sus reminiscencias con la narrativa existente y producida por escritores mucho más prestigiosos que él.

\section{Entre las ciudades y las aldeas del Nuevo Mundo}

Combinando los datos de algunos de mis estudios ${ }^{4}$ con los ofrecidos por Francesco D’Esposito ${ }^{5}$ y María Justina Sarabia Viejo ${ }^{6}$ sobre la presencia italiana en el Nuevo Mundo, emerge que entre 1492 y finales del siglo XVI 384 italianos se mudaron a los territorios que se acababan de descubrir. De ellos 182 llegaban de Liguria, ${ }^{7} 53$ de Toscana, 43 de las regiones de la Italia meridional, ${ }^{8} 15$ de Lombardía, 14 de Véneto, 10 de Córcega, 5 de Cerdeña, 3 de Lacio, 2 de Umbría, 2 de Emilia-Romaña; a estos se añadirían 55 personas de las que no sabemos sus regiones de procedencia.

$\mathrm{Su}$ presencia se registra un poco por todas partes. De la tabla 1 emerge que los italianos activos en América Central eran los más numerosos. También era elevado el número de los que junto a los conquistadores se habían mudado a la región de Río de la Plata y a los centros argentíferos peruanos y bolivianos. De todas formas, cualquiera que fuera la región elegida para probar fortuna, mercaderes y viajeros que desembarcaban en las Américas, tenían el primer impacto con el área caribeña, en particular con La Española y el puerto de Santo Domingo que muy pronto se dotó de las infraestructuras necesarias para el atraque de las embarcaciones y para la descarga de las mercancías. De las palabras de Galeotto Cei se deduce que para entrar con seguridad en la escala de la principal ciudad de la isla era

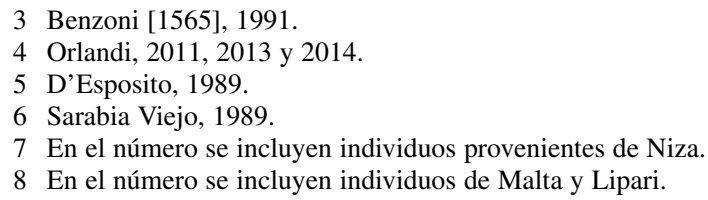


necesario llegar desde Levante porque, en caso contrario, las corrientes provocadas por la confluencia del río Ozama con el océano, empujaban a las embarcaciones contra algunas rocas. Siempre por razones de seguridad, era oportuno que las naves no superaran las 500 toneladas y para descargarlas habían sido construidos «un poco de muelle» y una aduana (llamada «terrazana») donde colocar las «cosas pequeñas». ${ }^{9}$

\section{TABLA 1}

PRESENCIA ITALIANA EN LAS INDIAS, SIGLO XVI

\begin{tabular}{|l|r|}
\hline \multicolumn{1}{|c|}{ Zona de destino } & Número \\
\hline Amazonia & 1 \\
\hline Antillas & 31 \\
\hline Chile & 37 \\
\hline Colombia & 1 \\
\hline Nueva España & 100 \\
\hline Perú y Potosí & 47 \\
\hline Río de la Plata & 64 \\
\hline Tierra Firme & 9 \\
\hline Venezuela y Cubagua & 22 \\
\hline Otros y no identificados & 72 \\
\hline Total & 384 \\
\hline
\end{tabular}

Desde el puerto hasta la ciudad a los ojos de nuestros viajeros aparecía inesperadamente bonita. Cuando llegó su primer obispo, Alessandro Geraldini, ${ }^{10}$ Santo Domingo había sido fundada hacía poco más de

9 Cei, 1992, 4-6. Los inconvenientes del puerto de Santo Domingo los señalaban todos los cronistas de aquel tiempo que subrayaban, como Galeotto Cei, las dificultades de atracar, la presencia de vientos no siempre favorables y la existencia de corrientes peligrosas. Todo esto afectaba negativamente al comercio y al desarrollo económico de la isla. Por eso no es extraño que se comenzara bien pronto a buscar soluciones alternativas. Al respecto, véase Gutiérrez Escudero y Laviana Cuetos, 1992, 546-553.

10 A causa de diferentes fechas de llegada, Cei pensaba que Geraldini era florentino, mientras que sus orígenes eran umbros (Cei, 1992, 5). Sobre la figura de Alessandro Geraldini véase D'Esposito, 2000. 


\section{5 años ${ }^{11}$ y el religioso no pudo hacer otra cosa que admirar lo que había sido construido en aquellos cinco lustros. En su historia comparaba las nuevas arquitecturas de las ciudades con las italianas:}

los edificios altos y bellos se levantan como en Italia, y el puerto puede incluso acoger todas las naves de Europa; las calles son anchas y rectas, al contrario que las vías de Florencia que no se pueden si tan siquiera comparar a esas: me di cuenta que en nuestros días las calles vuelven a tomar la amplitud que tenían en tiempos pasados. ${ }^{12}$

La comparación con Florencia no tiene que sorprender, la ciudad toscana era la cuna del Renacimiento que probablemente el religioso conocía. Como puede intuirse la atención del obispo se concentró en la iglesia principal que había sido levantada después del descubrimiento. De esta manera el obispo recordaba el momento en el que la vio:

Cuando entré en la iglesia edificada con vigas de madera, barro y arcilla, me estremecí: mi pueblo, que había prestado tanto cuidado a la construcción de las casas en las que vivirán solamente por pocos años, no se había puesto ningún cuidado en la construcción de la iglesia, que será para siempre un lugar de paz para todos. Por eso maduró en mi mente el pensamiento que esta iglesia tenía que ser obra de obispos: reuní por este motivo, en la sede arzobispal, a los magistrados y al pueblo, y después de haber rezado por tres veces en voz alta, pedí a todos una ayuda. ${ }^{13}$

11 Según la tradición, el primer asentamiento está fechado en 1494 o 1496 y fue obra de Bartolomeo Colombo. En cualquier caso, sobre la datación de la fundación de Santo Domingo existen distintas posiciones. Véanse, entre otros: Utrera, 1958, 221-261; Gutiérrez Escudero y Laviana Cuetos, 1992, 524-529; y Moya Pons, 1974, 57. Cuando Geraldini llegó (en 1519 según Francesco D’Esposito y en 1520 según Alessandro Geraldini descendiente del religioso), la ciudad ya había sido trasladada a su posición actual por Nicolás de Ovando. D’Esposito, 2000. Geraldini, 1991, 358.

12 «Ipsa enim aedificia ritu Italiae alta et pulchra sunt, ipse portus omnium navium Europae capax, ipsae viae latae, et rectae, ut viae Fluentinae, nullo modo comparandae iis sint, quamdam antiqui saeculi amplitudinem nostro tempore surgere conspexi» (Geraldinus, 1631, 199-200). «Gli edifici alti e belli sono innalzati come in Italia, e il porto può addirittura ospitare tutte le navi d'Europa; le strade sono larghe e diritte, così che le vie di Firenze non sono neppure paragonabili ad esse: mi resi conto che ai nostri giorni le strade riprendono l'ampiezza che avevano nei tempi passati» (Geraldini, 1991, 369).

13 «Postea cum templum Episcopale adirem, e tignis, e coeno, e luto erectum ingemui: populum meum tantam curam in aedibus privatis posuisse, quae breve ei domicilium daturae sunt, et nullum consilium in templo aedificando tenuisse, in quo pepetuum eis receptaculum futurum est. Itaque mecum animo evoluens hoc opus Episcoporum esse, populo, et magistrato in sede Episcopali coadunato, et oratione ibi publice ter habita adeo omnes movi» (Geraldinus, 1631, 200-201). «Quando entrai nella chiesa edificata con travi di legno, fango e argilla, provai una stretta al cuore: il mio popolo, che aveva posto tanta cura nel costruire le abitazioni che gli saranno dimora per pochi anni soltanto, non si era dato alcuna pena nella costruzione di una chiesa, che sarà per sempre un luogo di pace per tutti. Così, maturò nella mia mente il pensiero che questa chiesa doveva essere opera di vescovi: riunii per questo motivo, nella sede arcivescovile, i magistrati e il popolo, e dopo aver pregato per tre volte ad alta voce, chiesi a tutti un aiuto» (Geraldini, 1991, 370). Poder disponer de iglesias adecuadas para el 
Geraldini no podía descuidar dos cuestiones: la construcción parecía demasiado modesta tanto para acoger a los fieles como para representar el centro de la naciente Iglesia local; además no disponía ni tan siquiera de una sede episcopal. Por eso, convencido de que todos le habrían ayudado, pidió al soberano uno de los dos palacios que la Corona poseía en Santo Domingo y al Papa indulgencias para recaudar fondos que pudieran ser destinados a la construcción de la catedral y del hospital. ${ }^{14}$ Las dificultades que Geraldini tuvo que afrontar en su conjunto no fueron pocas, y por eso la primera piedra fue colocada en 1521 y las obras se iniciaron dos años después.

El obispo no vio el final de la obra, de hecho murió el 8 marzo de 1524 mientras que la catedral fue terminada en 1541. Su cuerpo reposa en un precioso sepulcro en el interior del templo. La fachada plateresca del edificio es un ejemplo del gótico tardío español, pero con la huella de las arquitecturas renacentistas toscanas en sus trazos arquitectónicos..$^{15}$

Sin embargo, aquellas formas tuvo que reconocerlas Galeotto Cei que, como hacíamos alusión, dejó La Española y el Nuevo Mundo cuando la iglesia ya había sido terminada desde hacía tiempo. Ante los ojos del mercader florentino la catedral se mostraba como «una bellísima iglesia con canónigos, contables y capellanes, muy bien oficiado». En aquella época la diócesis que, según decía, tenía unos ingresos anuales de 5.000 ducados, era un arzobispado del que eran sufragáneos los obispos de San Juan de Puerto Rico y de Cuba, el de Venezuela, Cabo de la Vela, Cartagena, Santa Marta y del Nuevo Reino de Granada. En la ciudad existían también «tres monasterios de monjes y dos parroquias y un hospital, muy nombrado, que sería suficiente a cualquier buena ciudad de España». ${ }^{16}$ En la misma época en que Santo Domingo era frecuentada por el mercader florentino,

ministerio religioso era un problema muy sentido por los misioneros presentes en los nuevos territorios. En una carta que Pietro Martire d'Anghiera escribió desde Toledo el 13 de junio de 1525 al arzobispo de Cosenza, Giovanni Ruffo, señalaba la misma dificultad para las iglesias construidas en Jamaica en las ciudades de Sevilla y Oristán. Los dos templos, edificados con vigas y paja, se incendiaron bien pronto, por lo que se decidió usar las rentas de Sevilla para iniciar la construcción de una iglesia y un sagrario de piedra, donde pudiera conservarse segura la Eucaristía. Pietro Martire d'Anghiera a Giovanni Ruffo, en Collo y Crovetto, 1991, 613-614.

14 D'Esposito, 2000.

15 Nuttgens, 2002, 233. Para un cuadro completo de la construcción de la catedral urbana, véase Palm, 1955, 25-51.

16 «un bellissimo duomo con canonici, rationieri et cappellani, molto bene uficiato» e «tre munisteri di frati et dua altre parrocchie et un spedale, molto nominato, che saria sufficiente a ogni buona ciptà di Spagna» (Cei, 1992, 4-6). 
también la estructura urbanística de la ciudad se había modificado convirtiéndose en:

bellísima de muchos edificios y casas, de modo que de su grandeza en España no hay mejores, por no decir de sus murallas del tamaño de Prato situadas a la altura del mar, con un poco de fortaleza no muy fuerte. ${ }^{17}$

La comparación con el tamaño de las murallas de Prato, ciudad cercana a Florencia capaz de acoger a más de 10.000 personas, nos es útil para intentar imaginar la dimensión de Santo Domingo, dotada entre otras cosas de adecuadas infraestructuras como algunas fuentes, que ofrecían agua buena para beber aunque «un poco salada para quien no está acostumbrado», y una fuente en la plaza de agua peor pero abundante y útil para «los servicios de las casas». ${ }^{18}$ Mucho se ha discutido acerca del abastecimiento de agua en la capital. Las opiniones de los cronistas son a veces divergentes, aunque es cierto que el agua que se obtenía de la fuente existente en la ribera derecha del Ozama no era de buena calidad, mientras era complicado y costoso proveerse «de la otra parte del río». Las alternativas y las soluciones que se intentaron para resolver estas dificultades fueron numerosas, pero solo una tuvo éxito: la construcción del acueducto que alcanzaba la plaza Mayor desde un pozo cercano al convento de San Francisco. ${ }^{19}$ Por tanto, es probable que el relato de Cei se refiera a la situación que se había creado gracias a esta intervención.

Si Santo Domingo era el centro principal de La Española, en la isla se encontraban muchos otros asentamientos urbanos de dimensión y funciones diversificadas. Cabe señalar sobre todo dos puertos: Puerto Real, «puerto bastante bueno», y Santa María de la Maguana, situado en cabo del Tiburón, puerto más grande, pero escasamente poblado. ${ }^{20}$ En el interior o en la costa pero con funciones económicas no relacionadas con el mar, encontramos «Gnoi», ${ }^{21}$ pequeña aldea con «casas de maderas, cañas y

17 «bellissima di moltie difiti et case, di modo che di sua grandezza in Ispagna non vi so meglio, per non dire tale cinta di mura della grandeza di Prato posta in piano in sul mare, con un poco di forteza non molto forte» (Idem). Sobre la construcción de las murallas y de las diversas estructuras defensivas de la ciudad, véase: Caro Álvarez, 1973. Gutiérrez Escudero y Laviana Cuetos, 1992, 553-565.

18 Cei, 1992, 5-6.

19 Gutiérrez Escudero y Laviana Cuetos, 1992, 534-546.

20 Cei, 1992, 6.

21 No hemos conseguido identificar esta localidad. Galeotto dice que se encuentra al este de Santo Domingo. Suponiendo que se trata de una italianización del nombre o de la lectura errónea de una abreviatura, quizá podría corresponder a Salvaleón. 
paja»,22 cuya población se ocupaba principalmente de la cría del ganado. Los habitantes de «Sabana», ${ }^{23}$ pueblo situado en la costa, se dedicaban a la agricultura y marginalmente a la cría. La «ciudad principal» era «Vega», ${ }^{24}$ cuya zona circundante había sido explotada al inicio por sus minas de oro agotadas en los años treinta y sucesivamente utilizada para la cría del ganado. A la misma actividad se dedicaban los habitantes de Monte Cristi, ${ }^{25}$ un «pueblecito» al noroeste de Santo Domingo. Según nuestro florentino aquellas aldeas estaban habitadas por cristianos que vivían en casas hechas de paja, cañas, palmas y maderas,

rodeadas y protegidas por muros, con aberturas cerradas con cañas, y así hacen casas con habitaciones, salas, pórticos, cocinas, establos y más trasteros, todo en una planta, sin utilizar ni tan siquiera un clavo, alambre, o cuerda, sino todo unido con ciertas como verbenas a las que llaman besciuccos. ${ }^{26}$

Los asentamientos más vastos y bien organizados eran los surgidos en las zonas donde se cultivaba y se elaboraba la caña de azúcar, cuyas plantaciones fueron apoyadas con fuerza por los españoles desde su llegada a la isla. ${ }^{27}$ Azua era la región dedicada por excelencia a la caña y a su costoso derivado. Se encuentran numerosos molinos entre los que destaca el de La Magdalena, de Giovanni Soderini, mercante florentino que había llegado a Santo Domingo entre 1535 y 1536 y que en los años cuarenta se había casado con Isabel, hija de Alonso Hernández de Las Varas, rico empresario azucarero cuya familia poseía la gran fábrica Santa Bárbara. Con aquella boda, Giovanni había entrado a formar parte de la oligarquía azucarera de La Española, que antes de otros grupos sociales pudo permitirse la construcción de casas de piedra. ${ }^{28}$ Empeñada en la producción del azúcar estaba también la población de San Juan de la Maguana, pequeño asentamiento no lejano de Azua, donde estaban en funcionamiento dos ingenios. ${ }^{29}$

22 «case di legnami, canne et paglia» (Cei, 1992, 6).

23 Hoy probablemente Sabana de la Mar.

24 Vega o Santiago de la Vega, hoy probablemente Santiago de los Caballeros.

25 Hoy probablemente San Fernando de Montecristi.

26 «intorniate e ferrate intorno per mura, con chiudende di canne, et così fanno case con camere, sale, loggie, cucina, stalla et più ripostigli, tutto a un piano, senza che v'entri un aguto, o filo, o fune, ma tutto legato con certe come vitalbe che dicono besciuccos». Cei, 1992, 7.

27 Por lo que respecta a las primeras actividades productivas del azúcar de las Antillas véanse: Cassá, 1977, 83-91. López y Sebastián y Del Río Moreno, 1992. López Morales, 1990. Ratekin, 1954. Wright, 1916. Una investigación más reciente es la de Stevens-Acevedo, 1995.

28 Stevens-Acevedo, 2005. Gutiérrez Escudero y Laviana Cuetos, 1992, 531.

29 La población local se ocupaba también de la cría. Cei, 1992, 6. 
Cei nos ofrece una descripción de una fábrica típica pero no dice nada sobre el coste de la instalación, que representaba la primera y fundamental movilización. Además, no tenían que ser menos gravosos los gastos por capital humano que aunque no estaba constituido por obreros sino por esclavos, 200 esclavos «negros o cristianos» podían costar al menos 30.000 ducados. Los pocos hombres libres eran individuos dotados de capacidades profesionales como el «facitore di forme» de azúcar, y los «7 u 8 capataces». Además había una mano de obra que no trabajaba directamente en el molino, sino en otras actividades colaterales que hacen pensar en la organización de la aldea: dos carreteros — uno de los cuales dedicado a la doma de los caballos y el cuidado de los bueyes,$-{ }^{30}$ un herrero, un carpintero, un artesano capaz de hacer carretas. Para vigilar la plantación eran necesarias al menos dos personas que proveían también al cultivo del maíz y de otros productos. Los hombres se ocupaban también de encontrar madera para las calderas de refinación que absorbían cada día 24 carretas de madera. La ausencia de una sola de estas competencias, comentaba Cei, habría hecho imposible «hacer algo bueno».

De lo expuesto se entiende que la industria azucarera condicionó bastante la organización de los territorios en los que se encontraba y no solo por la presencia de los molinos para el azúcar, maquinarias que podían ser movidas por el agua (ingenios) o por la fuerza animal (trapiches). ${ }^{31}$ «Un buen ingenio - escribía Cei- es como un pequeño pueblo».

Se estaba en los primeros decenios del Quinientos y los procesos productivos no debían estar bien organizados todavía. Para imaginarlos puede ser de gran ayuda el cuadro de Giovanni Stradano que da una idea de las múltiples actividades alrededor del líquido recogido de la estrujadura de las cañas en una fábrica de azúcar.

En la época de Cei, él mismo contaba que había muchos molinos de agua, movidos por ruedas o por rodetes. En todos los casos aquellas fábricas presentaban elementos de diseminación de las varias fases productivas que se realizan a menudo en lugares contiguos pero separados. Además de la casa del molino podía estar la de la purga y la de las «piliere» donde «conservaban los azúcares». Es inútil decir que en aquel aglomerado se encontraban edificios o cabañas destinados a diferentes usos. Está claro que una organización articulada de esta manera y un personal tan

30 Según Cei se necesitaban al menos 70 u 80 pares de bueyes. Ibidem, 25.

31 Sobre las diferentes tipologías de molinos de azúcar véase Stevens-Acevedo, 2009. 
numeroso exigiera también alojamientos adecuados que, a diferencia de los de otras realidades rurales y mineras del Nuevo Mundo, estaban hechos «de piedra y de tierra, cubiertos de tejas o de esmalte para protegerlos del fuego que provocaba grandes daños». ${ }^{32}$ Muy racional y bien organizada nos parece la aldea de una plantación ochocentista representada en un diseño publicado por Edward Crain en su estudio sobre las arquitecturas históricas del Caribe ${ }^{33}$ que representa probablemente el punto de llegada de un proceso de adaptación de las primeras aldeas azucareras de aquellas tierras. En aquellas imágenes podemos reconocer un contexto territorial más amplio hecho de muchos terrenos sobre los que cultivar la caña. Casas, fábricas y cabañas situadas dependiendo de la presencia de al menos un curso de agua para el molino e indispensable para regar los terrenos, sobre todo después la quema de los rastrojos. ${ }^{34}$

La Española a mediados del siglo XVI mostraba una economía en expansión que era debida a la producción de azúcar y a la cría de ganado. El contexto social de aquellos años había cambiado mucho, puesto que se había agotado la fase basada en la búsqueda del oro. Esta había comenzado con el gobierno de Nicólas de Ovando, quien desde su llegada (1502) había organizado la explotación de los yacimientos de San Cristóbal y del Cibao, que había provocado la extinción de los taínos y determinado la importación de los esclavos africanos..$^{35}$

En el período observado por nosotros, una significativa parte de la población de la isla, no ocupada en la producción de azúcar, se dedicaba a la cría del ganado y a la producción de pieles, aquellas «pieles de las Indias» que encontraron inmediata y consistente salida en los mercados europeos. Ya en 1531 operadores económicos florentinos activos en Andalucía pedían enviar a Toscana 200 pieles de las Indias «para una prueba», ${ }^{36}$ para verificar cómo los consumidores respondían a una calidad hasta aquel momento desconocida. Gracias a la intermediación mercantil de los

32 «di pietra et di terra, coperte di teghole o di smalto per causa del fuoco che vi fa gran danno» (Cei, 1992, 7).

33 Crain, 1994, 52.

34 Cei, 1992, 24.

35 Mira Caballos, 2000, 33-140. Cantù, 2007.

36 Archivo de Estado de Florencia (en adelante ASF), Libri di famiglia e di commercio, 224, Pisa-Cádiz, Francesco Botti a Iacopo e Giovambattista Botti, Pisa, 23 de agosto de 1531, c. 18. La primera «valuta di mercanzia», signo indudable de una presencia continua y consistente en la plaza pisana, está fechada en 1533, en aquella ocasión Francesco Botti escribía que las pieles de India «ci se n’è vendute buona partita a lb. 16 e 17 el pezzo, l'uno per l'altro sim tara». Ibidem, Francesco Botti a Iacopo e Giovambattista Botti, Pisa, 29 de octubre de 1533, c 174r. 


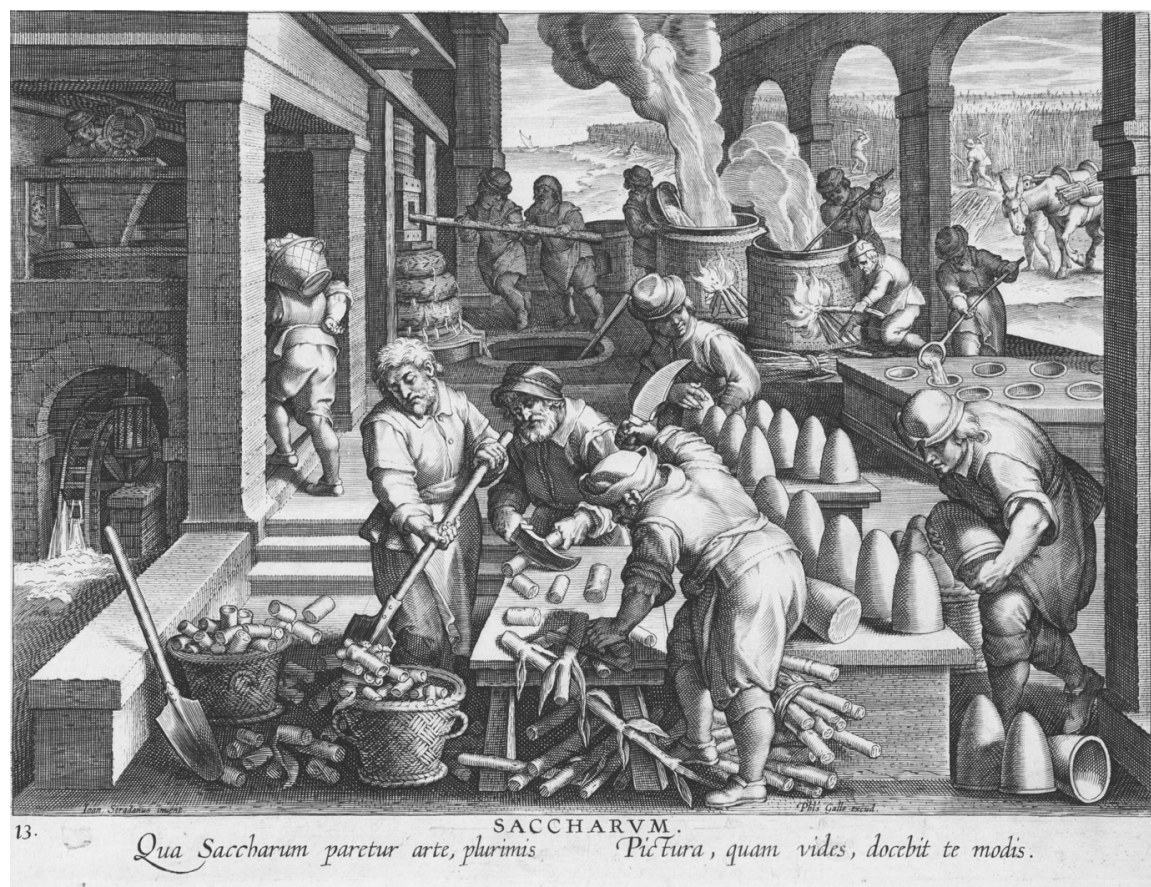

Giovanni Stradano. «Azúcar. Cualquiera que sea la forma con la que se hace el azúcar / te lo muestra de muchas maneras, el cuadro que ves». Nova Reperta, RB78222, p. 13, The Huntington Library, San Marino, California.

europeos, entre los que sobresalían los italianos, la difusión en el Mediterráneo de las pieles americanas fue más rápida que la que se verificó del azúcar. ${ }^{37}$ De nuestros documentos emerge que los españoles, ayudados por operadores económicos italianos, sobre todo genoveses y florentinos, daban un fuerte impulso a la economía de la isla. En este cuadro se entienden los procesos de desarrollo urbanístico de Santo Domingo que se había dotado de una Casa de Moneda, instituida en $1536 .{ }^{38}$ El establecimiento

37 Orlandi, 1998

38 En su relato, Galeotto Cei recuerda mal esta fecha, puesto que indica que la fundación de la Casa de Moneda se produjo en 1525 (Cei, 1992, 6). Según Erwin Walter Palm, la Casa de la Moneda «instituida en 1536 un año más tarde que la de México fue establecida después de 1540 cuando aún se pide "que tuviera efecto la merced de que en esta ciudad hubiera Casa de Moneda para labrar aquí plata y vellón". En abril de 1541 el monarca efectivamente manda acuñar moneda de vellón y cobre» (Palm, 1955, 112). 
acuñaba solamente monedas de plata y cobre, que también se acuñaban en Nueva España, ya que en ninguna parte de las Indias se forjaba el oro, mercancía preciosa para vender a los europeos.

La Española también era lugar de salida para quien quería mudarse hacia Tierra Firme, la Nueva España, Venezuela, Cubagua y Perú.

La Tierra Firme correspondía a la zona alrededor de Panamá. Expuesta sobre el mar Caribe, a 246 leguas $^{39}$ de Santo Domingo, se encontraba Nombre de Dios. ${ }^{40}$ Allí donde hacían etapa los galeones de la carrera de Indias, se encontraban numerosos mercaderes europeos listos para participar en el tráfico de plata que llegaba desde Perú y Charcas. El propio Galeotto encontró a un savonés, Marco Rocchetta, que le alojó en su casa. ${ }^{41}$

Para los tráficos de plata era al mismo tiempo importante «el puerto y el pueblo» de Panamá, que se asomaba al océano Índico y distaba 20 leguas de Nombre de Dios. El puerto de Panamá se encontraba en una ensenada situada bajo altísimas montañas abiertas a tramontana, la escala era segura, protegida por algunas rocas que los hombres de aquella época usaban como muelle. No estaba defendida por una fortaleza, sino solamente por algunos bastiones más bien débiles ya que estaban hechos de arena, pero bien dotados de artillería. En cualquier caso su posición lo hacía muy difícil de tomar y el mismo Cei, quizás no sin alguna exageración, decía que para apropiarse del puerto habría sido necesaria una docena de naves de 100 toneladas capaces de desembarcar dos mil hombres. Sin embargo la zona habitada se encontraba en una pequeña llanura a los pies de las montañas y cercana al mar. Se trataba de un área ocupada por pantanos y por tanto muy húmeda. Las casas eran de planchas de madera cubiertas de tejas. Para su construcción no se podía utilizar la madera de las montañas colindantes porque estaba demasiado impregnada de agua, y por eso se hacía llegar desde las islas circunstantes. Para protegerse de la humedad algunas casas disponían de una especie de entreplanta donde tumbarse, porque quien «no duerme en palco vive poco y es poco sano». ${ }^{42}$ Es probable que Galeotto aludiese justo a este tipo de casa, cuando decía que en Panamá el coste de los alquileres era elevadísimo, oscilaba entre los 400 y los 500 ducados de alquiler al año.

39 El florentino precisaba que se trataba de leguas de cuatro millas cada una. Cei, 1992, 38.

40 Idem.

41 Idem.

42 Ibidem, 39. 
Los colonos habían introducido la cría del ganado importado de Santo Domingo pero, como ya hemos indicado, la economía local estaba unida esencialmente a los tráficos de la plata. De hecho, en la ciudad se encontraban muchos mercaderes que, en espera del metal precioso, «jugaban todo el día al fresco intentando no sudar». ${ }^{43}$

Como hemos visto, en Nueva España, la parte de América Central que el florentino Giovanni Nicolozzi llamaba «tierra que te hace olvidar» ${ }^{44}$ por las grandes riquezas que habría hecho olvidar a cualquiera del deseo de regresar a la patria, operaba un buen número de mercaderes italianos. Entre los toscanos los más activos eran sin duda los sieneses, ${ }^{45}$ que comerciaban en la compra de azúcar y cochinilla vendiendo paños, telas y sedas. Entre los productos americanos merece un breve estudio la cochinilla, el colorante que Jacques Heers ha definido como la tercera riqueza del Nuevo Mundo, tras la plata y el oro. ${ }^{46}$ Por un lado, es muy probable que hayan sido mercaderes de Burgos quienes la hicieron conocer a los florentinos (la primera noticia data de 1541), ${ }^{47}$ por otro, sin embargo, es cierto que los operadores toscanos se movieron rápidamente para controlar el mercado. El poder tintóreo de la cochinilla era superior al del kermes asiático y al de la grana, nació de esta manera una verdadera y propia guerra comercial entre cochinilla y grana que vio como vencedor al colorante americano. ${ }^{48}$ Cabe destacar que entre agosto de 1541 y enero de 1564, el grupo florentino de los Botti, que actuaba entre Andalucía y Toscana, comerció unas dos toneladas. ${ }^{49}$

Las ciudades de la región mexicana vienen descritas en una carta enviada por el monje misionero boloñés Francesco Allé a sus hermanos y al superior provincial Clemente da Moneglia. Francesco contaba cómo en México se encontraban ciudades más grandes que las europeas que llegaban a tener hasta 80.000 vecinos, las casas eran bajas y bien construidas,

43 Ibidem, 38-39.

44 Giovanni Nicolozzi, «Lettera dal Messico», en Collo y Crovetto 1991, 451-456.

45 Orlandi, 2014.

46 Heers, 1961, 1.

47 ASF, Miscellanea Medicea, 107/1, Florencia-Sevilla, Matteo Botti a compagnia Botti, Florencia, 30 de julio de 1541, c. 112r. Ibidem, Matteo Botti a compagnia Botti, Florencia, 8 de agosto de 1541 , c. $114 \mathrm{v}$.

48 En los años cuarenta del Quinientos mercaderes florentinos escribían que no habían «trovato da dar via, né a baratto, quella poca grana che qui (Toscana) quasi non se n'usa che ànno tinto molti panni con la cocciniglia». ASF, Miscellanea Medicea, 107/2, Florencia-Cádiz, Matteo Botti a compagnia Botti e Peri, Florencia, 12 de diciembre de 1545, c. 170r.

49 Orlandi, 1998, 485-487. 
no protegidas por muros. De hecho habían sido los españoles los que habían enseñado a los nativos a defender las ciudades con una muralla. ${ }^{50}$

Sin duda el centro más conocido era Ciudad de México que provocaba en todos los visitantes europeos una sensación maravillosa. Pietro Martire d'Anghiera en 1521 escribía: «dicen que aquella ciudad consta de un número de cincuenta mil casas» y todas de piedra; en ella también se encuentran muchos palacios principescos porque habían sido numerosos los nobles de la corte de Moctezuma. ${ }^{51}$ Rodeaban la laguna otros seis centros fortificados todos ellos construidos con casas de piedra en parte sobre el agua y en parte sobre la tierra firme. El citado Giovanni Nicolozzi, que había llegado a aquellos territorios en 1536, la describía así en una carta dirigida a su padre:

está fundada como Venecia en un gran lago que tiene 60 millas, todo de agua y está fabricada con edificios muy buenos y todos de piedra, y así de buenas casas, como sucede en Venecia, hechas por mano de los indios. ${ }^{52}$

El trecho de costa entre Cabo de la Vela y Coro mostraba que los asentamientos humanos se vinculaban al deseo o la necesidad de vivir cerca del mar. A lo largo de aquel litoral, «los indios tenían sus casas y casi sobre el agua y de muchas barcas, como canoas, pequeñas y grandes, y están siempre en el agua y son muy hábiles y valientes en ella». ${ }^{53}$ En 1544 , Coro se había visto reducida a diez casas de paja distantes dos leguas del mar. Sus estructuras eran las que habían dejado abandonadas la población local y sustituidas rápidamente por los conquistadores. La iglesia episcopal que para ser hecha de madera, cañas y paja parecía bonita, ${ }^{54}$ había sido realizada utilizando la gran casa del señor del lugar, el «cacique Manarve». Los cristianos que habitaban en Coro vivían en míseras condiciones, sembrando maíz y criando gallinas que vendían a los habitantes del interior y de Cabo de la Vela. ${ }^{55}$ Los españoles habían llevado también ganado desde las

50 Francesco Allé, «Lettera scritta dalla Città del Messico», en Collo y Crovetto, 1991, 429440, cita 436. La fecha de la misiva es incierta, seguramente posterior a 1524.

51 Pietro Martire d'Anghiera, Lettera ai Marchesi Pedro Fajardo e Luis Hurdado de Mendoza, Valladolid, 7 de marzo de 1521, en Collo y Crovetto, 1991, 607-608, cita 608.

52 «è fundata come Venezia in gran lago che dura da 60 miglia, tutto di acqua ed è fabbricata con edificii molto buoni e tutti di pietra, e così di buone case, come è a Venezia, fatte per mano degli indiani» (Nicolozzi, «Lettera dal Messico», en Collo y Crovetto, 1991, 455).

53 «l'indi hanno le loro case e quasi sull'acqua et di molte barche, cioè canoe, piccole e grande, et sono sempre nell'acqua e molto destri e valenti in essa» (Cei, 1992, 41).

54 Idem.

55 Idem. 
islas cercanas: vacas, caballos, asnos, cabras y ovejas. Los pastizales eran ligeramente salinos por su cercanía al mar, hacían sus carnes excelentes, buenísimas como las franceses, recordaba Galeotto.

$\mathrm{Al}$ este de Coro los mercaderes y los viajeros italianos encontraban los centros de Cumaná y Maracapaná. Las dos localidades habían conseguido cierta importancia y habían crecido sobre todo en el período en el que florecía la pesca de perlas en las islas de Margarita y Cubagua que se encontraban justo enfrente de las dos localidades costeras.$^{56}$ Según Galeotto Cei, en Cubagua para acoger a los europeos empeñados en el aprovechamiento de las zonas perlíferas, Iacopo Castiglione había hecho construir sesenta casas todas de ladrillos y dispuestas como un pequeño burgo que llamó «Nueva Cádiz», donde se construyó también un monasterio por obra de cuatro monjes franciscanos que hicieron llegar de Santo Domingo. ${ }^{57}$ Para Cubagua era fundamental la aldea de Cumaná que se encontraba en la desembocadura del homónimo río donde los habitantes de la isla de las perlas se abastecían de agua dulce. Para facilitar las operaciones de aprovisionamiento, los españoles habían edificado una fortaleza de madera en la que amarrar los barcos que llegaban desde Cubagua. En el período de máximo esplendor de la pesca, entre los años 1520 y 1530, se levantó otra fortificación en tierra firme que fue destruida a causa de las lluvias que habían hecho que se desbordara el río. ${ }^{58}$ En 1541, cuando se encontraba allí Girolamo Benzoni, todavía había cuatro o cinco casas hechas de cañas y, parece entenderse, que se encontrasen más o menos en la zona donde el capitán Diego de Ocampo edificó la ciudad de Toledo. ${ }^{59}$ De hecho, Ocampo ordenó a los indios que construyeran veinticinco casas de paja justo en la desembocadura del río y llamó al nuevo asentamiento «Villa de Toledo». ${ }^{60}$

Maracapaná o «Amarcapanná», como la llamaba Benzoni, era un núcleo de unas cuarenta casas donde, según lo que se decía, residían cuatrocientos españoles que cada año elegían entre ellos a un capitán. ${ }^{61}$

La acción de penetración de los italianos en los territorios de la América meridional no se limitó a la zona costera. Algunos de ellos llegaron hasta Potosí. Galeotto Cei, en el período de su vida en que acompañó

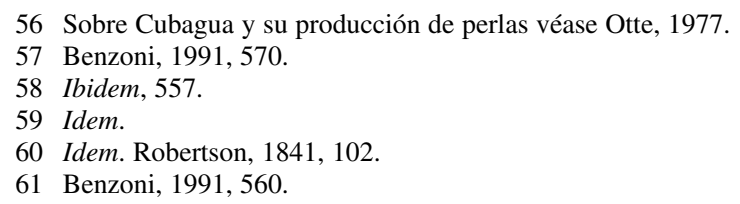


a los conquistadores en la década de 1540, llegó hasta las zonas interiores de Venezuela y participó en la fundación de Barquisimeto y más al sur, el 30 noviembre de 1545, de El Tocuyo, que se concretó en un grupillo de casas hechas de cañas, paja y maderas de las que la zona era particularmente rica.$^{62}$ El florentino, que quería alcanzar el mítico Perú, prosiguió todavía más al sur. Superó la frontera con Venezuela para pasar a la hoy Colombia. En los primeros días de junio de 1551 estaba en Tunja, poblada por setenta cristianos que la habitaban de forma estable. A ellos se añadían presencias esporádicas que hacían subir la población a 250 o 300 personas. Justo en aquellos años se estaban comenzando a levantar casas de piedra, ladrillo y tierra. Había llegado a la región que los indios llamaban Bogotá y los españoles Nuevo Reino de Granada, porque era fría como las montañas de Sierra Nevada. ${ }^{63}$

Otra «ciudad principal» era Santa Fe donde se encontraba una cancillería real y dos auditores. Muchas de sus casas eran de piedra y tierra y su coste oscilaba entre los 2.000, 3.000 y 8.000 ducados. En ellas residían 400 cristianos de los que solo 80 eran vecinos y poseían reparticiones, territorios que cada año daban además de maíz, trigo y cebada, un tributo de 400, 500 o 1.000 ducados de oro de baja ley (entre 7 y 10 quilates). En algunos casos se encontraban monedas con solo 4 quilates de metal precioso mezclado con latón y cobre. ${ }^{64}$

Cei visitó también Pamplona, pequeño centro en el que habitaban 150 cristianos, y Vélez, más pequeña que Tunja y poblada por personas «de más humilde condición». ${ }^{65}$ No consiguió llegar a la Villa Imperial de Potosí, mientras que sí la alcanzó su conciudadano Niccolò del Benino, que después de mil vicisitudes se convirtió en un rico empresario de la minería, ya que compró y explotó con éxito una veta de plata en la Veta Rica del Cerro de Potosí. Benino describía la rica ciudad española como «un castillo o población» en la que normalmente vivían 800 hombres junto a 20.000 indios empeñados en el trabajo de extracción de la plata. A pesar de encontrarse a 2.000 metros de altitud, entre sus calles y sus casas se encontraba de todo como en ningún otro lugar de aquella región. ${ }^{66}$

62 Cei, 1992, 45.

63 Ibidem, 69.

64 Idem.

65 Ibidem, 69-70.

66 Niccolò del Benino, «Copia di parte di una lettera dal Perù», en Collo y Crovetto, 1991, 523-545, cita 542. Miroglio, 1993. 


\section{Conclusiones}

Hemos visto que las historias de algunos de los italianos que dejaron el Viejo por el Nuevo Mundo, a pesar de ser algo desordenadas e incompletas, nos ayudan a entender cómo los procesos de urbanización de las ciudades más ricas e importantes se vieron condicionados principalmente por los estilos europeos, mientras en las realidades más pobres parecía prevalecer la lógica y las formas de las configuraciones originales. En las zonas caracterizadas por actividades del sector primario y del secundario, las exigencias de racionalización daban lugar a una síntesis entre la tradicional cabaña y las más o menos innovadoras plantas productivas. Parece ser que los españoles, al menos inicialmente, construyeron sus casas siguiendo los trazos distintivos de las poblaciones indígenas. Se trataba de casas con un solo piso, parecidas o similares a las cabañas. En las aldeas de La Española los alojamientos estaban hechos de paja, cañas, palmas y madera unidos no con clavos o cuerdas sino con «besciuccos», tipo de lianas que los nuestros llamaban verbenas y que formaban parte de las técnicas de construcción locales. Sin embargo, la estructura interior de los alojamientos era la típica del Viejo Mundo: los espacios estaban divididos en cámaras, salas, cocina, lonjas, y cuadras.

Como se puede intuir, la madera constituía el material de construcción más usado en todas partes. En Panamá las casas eran de madera cubiertas de tejas y también en Coro para los alojamientos se utilizaba la madera, ejes y mesas se usaron para la creación de nuevas aldeas como Barquisimeto y El Tocuyo en lo que hoy es Colombia.

Con el pasar del tiempo y sobre todo en los centros en los que la población residente estaba creciendo, los españoles comenzaron a levantar edificios e infraestructuras urbanas cada vez más parecidas a las europeas. Alessandro Geraldini contaba que los edificios de Santo Domingo eran «altos», es decir con más plantas y eran «levantados como en Italia», las calles también le parecían anchas y rectas, incluso más que las florentinas.

No solo la ciudad principal de Cubagua, llamada «Nueva Cádiz», contaba sesenta casas todas de ladrillos y colocadas como en un pequeño burgo. Todos saben que el burgo constituye la estructura urbanística típica de las ciudades medievales de Italia central. Como hemos visto, fueron los españoles los que protegieron estas nuevas o renovadas ciudades con murallas, costumbre que las poblaciones locales no conocían. También los 
bastiones y las fortalezas de madera o arena que se levantaron en Panamá o en Cumaná, fueron introducidos por los europeos.

En el ámbito de las grandes ciudades no podían faltar los edificios del poder político y religioso. Una atención particular se reservaba a las iglesias, monasterios y hospitales.

Con el tiempo incluso los materiales de construcción se modificaron y se comenzaron a usar siempre más a menudo piedra y ladrillos.

Queremos concluir estas consideraciones nuestras con la descripción de una «noble ciudad en las Indias» que un viajero anónimo, el 25 de septiembre de 1535, llamaba «Zhaval» y que hasta ahora nadie ha sido capaz de identificar:

Tiene un puerto bellísimo y las murallas alrededor por el lado de tierra son de madera, juncos esmaltados, y dentro duplicadas con tierra, casi como a la usanza de los bastiones de Italia, y miden más o menos cuatro pasos. También las casas están esmaltadas con finísima arcilla, con un cierto color cocido que parecen vitrificadas tanto dentro como fuera como se colocan en nuestras casas los platos y los coladores y decoradas con figuras, como solamente ellos saben hacer y que parecen las cosas más bonitas del mundo. El tejado está cubierto con finísimas cañas blancas. Todas están en una planta, con habitaciones y salas y otros cuartos bellísimos. Hay solo un templo que está en el medio de la ciudad, de gran tamaño, en el que hay un sacerdote viejo. ${ }^{67}$

Recibido el 30 de octubre de 2014 Aceptado el 1 de junio de 2015

\section{Bibliografía}

Benzoni, Girolamo: «Historia del Mondo Nuovo» [1565], en Collo, Paolo y Crovetto, Pier Luigi (eds.), Nuovo Mondo. Gli Italiani, 1492-1565, Torino, Einaudi, 1991, 547-589.

Cantù, Francesca: Identità del Nuovo Mondo, Roma, Viella, 2007.

Caro Álvarez, José A.: Las murallas de Santo Domingo, Santo Domingo, 1973.

Cassá, Roberto: «La industria azucarera del siglo XVI», Historia Social y Económica de la República Dominicana, I, Santo Domingo, 1977, 83-91.

67 «Ha un bellissimo porto, e le mura d'intorno da la banda terrestre sono de legnami, cioè vimene smaltate, e dentro duplicate con terra, quasi a la usanza de li bastioni d'Italia, e sono alte quattro passa o circa. Le case pure similmente sono smaltate con creta finissima, con una certo colore cotto che paiono dentro e fuora invetriate sì come sono li piatti e scutelle ne le bande nostre, talché lustrate e pentate con certe loro figure al modo suo, paiono a mirare la più bella cosa del mondo. Il tetto è coperto de canne sottilissime e bianche. E tutte sono a piano, con camere e sale e altre stanze bellissime. Un tempio solo è nel mezzo della città, de spaciosa grandezza, nel quale è uno sacerdote vecchio». (Anónimo, «Lettera de la nobil città nuovamente ritrovata alle Indie...», en Collo y Crovetto, 1991, 443-449, cita 446). 
Cei, Galeotto: Viaggio e relazione delle Indie (1539-1553), edición de Francesco Surdich, Roma, Bulzoni Editore, 1992.

Collo, Paolo y Crovetto, Pier Luigi (eds.): Nuovo Mondo. Gli Italiani, 1492-1565, Torino, Einaudi, 1991.

Crain, Edward E.: Historic Architecture in the Caribbean Islands, Gainesville, University Press of Florida, 1994.

D’Esposito, Francesco: «Presenza italiana tra i "Conquistadores" ed i primi colonizzatori del Nuovo Mondo (1492-1560)», en Presencia italiana en Andalucía, siglos XIV-XVII. Actas del III Coloquio Hispano-Italiano, Sevilla, Escuela de Estudios Hispano-Americanos, 1989, 493-517.

D’Esposito, Francesco: «Alessandro Geraldini», en Dizionario Biografico degli Italiani della Treccani, vol. 53, Roma, 2000, http://www.treccani.it/enciclo pedia/alessandro-geraldini_\%28Dizionario_Biografico\%29/

Geraldini, Alessandro: «Itinerarium ad regiones subaequinoctiali plaga constitutas», en Collo, Paolo y Crovetto, Pier Luigi (coords.), Nuovo Mondo. Gli Italiani, 1492-1565, Turín, Einaudi, 1991, 357-391.

Geraldinus, Alexander: Itinerarium ad regiones sub aequinoctiali plaga constitutas, Roma, Typis Guilelmi Facciotti, 1631.

Gutiérrez Escudero, Antonio y Laviana Cuetos, María Luisa: «Las primeras obras públicas en el Nuevo Mundo y su financiación: Santo Domingo 1494-1572», en Actas del Congreso de Historia del Descubrimiento: 1492-1556, Madrid, Real Academia de la Historia, 1992, t. III, 523-577.

Heers, Jacques: «La búsqueda de colorantes», Historia Mexicana, XI/1, México, 1961, 1-27.

López Morales, Humberto: «Orígenes de la caña de azúcar en Iberoamérica», en La caña de azúcar en tiempos de los grandes descubrimientos (1450-1550). Actas del Primer Seminario Internacional, Granada, Ayuntamiento de Motril, 1990, 189-208.

López y Sebastián, Lorenzo E. y Del Río Moreno, Justo L.: «Comercio y trasporte en la economía del azúcar antillano durante el siglo XVI», Anuario de Estudios Americanos, XLIX, Sevilla, 1992, 57-87.

Mira Caballos, Esteban: Las Antillas Mayores, 1492-1550 (Ensayos y documentos), Madrid, Iberoamericana, 2000.

Moya Pons, Frank: Historia colonial de Santo Domingo, Santiago de los Caballeros, Universidad Católica Madre y Maestra, 1974.

Miroglio, Andrea: «Niccolò del Benino. L'avventura di un mercante-imprenditore fiorentino in America», Rivista Geografica Italiana, Año del centenario, 100, Firenze, 1993, 463-478.

Nuttgens, Patrick: Storia dell'architettura, Milano, Mondadori, 2002.

Orlandi, Angela: «Zucchero e cocciniglia dal Nuovo Mondo, due esempi di precoce diffusione», en Cavaciocchi, Simonetta (coord.), Prodotti e tecniche d'Oltremare nelle economie europee. Secc. XIII-XVIII, Atti della 
«Ventinovesima Settimana di Studi», [Prato] 14-19 aprile 1997, Firenze, Le Monnier, 1998, 477-487.

Orlandi, Angela: Mercanzie e denaro: la corrispondenza datiniana tra Valenza e Maiorca (1395-1398), València, Universitat de València, 2008.

Orlandi, Angela: «Al soffio degli Alisei. Mercanti fiorentini tra Siviglia e il Nuovo Mondo», Archivio Storico Italiano, CLXIX, Firenze, 2011, 477-505.

Orlandi, Angela: «Fiorentini alla ricerca del Nuovo Mondo», en Azzari, Margherita y Rombai, Leonardo (coords.), Amerigo Vespucci e i mercanti viaggiatori fiorentini del Cinquecento, Firenze, FUP, 2013, 131-156.

Orlandi, Angela: «Dall'Andalusia al Nuovo Mondo: affari e viaggi di mercanti toscani nel Cinquecento», en Pinto, Giuliano; Rombai, Leonardo y Tripodi, Claudia (coords.), Vespucci, Firenze e le Americhe, Firenze, Olschki, 2014, 63-86.

Otte, Enrique: Las perlas del Caribe: Nueva Cádiz de Cubagua, Caracas, Fundación John Bulton, 1977.

Palm, Erwin Walter: Los Monumentos Arquitectónicos de La Española, vol. II, Ciudad Trujillo (Rep. Dominicana), Universidad de Santo Domingo, 1955.

Ratekin, Mervyn: «The Early Sugar Industry in Española», Hispanic American Historical Review, XXXIV-1, Durham, NC, 1954, 1-19.

Robertson, Guglielmo: Storia dell'America, Palermo, Imprenta de Federico Garofalo, 1841.

Sarabia Viejo, María Justina: «Presencia italiana en la Nueva España y su conexión sevillana (1520-1575)», en Presencia italiana en Andalucía, siglos XIV-XVII. Actas del III Coloquio Hispano-Italiano, Sevilla, Escuela de Estudios Hispano-Americanos, 1989, 427-462.

Stevens-Acevedo, Anthony: «Esclavos, empresarios azucareros y transacciones económicas en el ingenio Santa Bárbara de la Isla Española de 1557», Ecos, 4, Santo Domingo, 1995, 31-55.

Stevens-Acevedo, Anthony: «The origins of the Colonial Sugar Oligarchy in La Hispañola: The Case of the Varas-Soderín-Castillo-Torres Clan in the Sixteenth Century», M.A. Thesis, Department of History, The City College of New York, 2005.

Stevens-Acevedo, Anthony: «El uso del molino de rodillos horizontales dobles en las haciendas azucareras de la Isla Española en el siglo XVI: Viejas y nuevas evidencias», O Açúcar antes e depois de Colombo. Seminario Internacional de História do Açúcar, Funchal, Madeira, Centro de Estudos de História do Atlântico, 2009, 70-126.

Utrera, Cipriano de: Para la historia de América, Santo Domingo, Impresora Dominicana, 1958.

Wright, Irene: «The Commecement of the Cane Sugar Industry in America, 15191538 (1563)», American Historical Review, XXI-4, Oxford, 1916, 755-780. 